\title{
Climate Variability and International Migration: The Importance of the Agricultural Linkage
}

\author{
June 19, 2016
}

\begin{abstract}
While there is considerable interest in understanding the climate-migration relationship, particularly in the context of concerns about global climatic change, little is known about its underlying mechanisms. In the paper, we combine a rich panel data on annual bilateral international migration flows with an extensive data on climate variability across the countries to investigate in-depth the climate-migration link. We find a positive and statistically significant relationship between temperature and international outmigration only in the most agriculture-dependent countries, consistent with the widely-documented adverse impact of temperature on agricultural productivity. Further, the temperature-migration relationship is nonlinear and resembles the nonlinear temperature-yield relationship. In addition, migration flows to current major destinations are especially temperature-sensitive. Policies to address issues related to climate-induced international migration would be more efficient if focused on the agriculture-dependent countries and especially people in those countries whose livelihoods depend on agriculture.
\end{abstract}

JEL codes: F22, J61, Q54

Keywords: International migration; Temperature; Agricultural productivity; Nonlinear effect.

(C) 2016. This manuscript version is made available under the Elsevier user license http://www.elsevier.com/open-access/userlicense/1.0/ 


\section{Introduction}

Climate change has become an increasing global concern as its current and future impacts are understood in greater detail (IPCC, 2014). One widely cited response to such impacts is the potential for large-scale displacement of segments of human population (Myers, 2002; Stern, 2007; Warner et al., 2009; Marchiori et al., 2012). Among all climate-induced migrants, those crossing the political borders would be a matter of particular concern as both receiving and sending countries are affected. Identification of the mechanisms underlying the climate-migration relationship would be useful to national governments and international agencies devising policies to manage migration flows.

Despite growing interest from policymakers and the general public, the quantitative literature on weather- and climate- induced migration is still in its infancy. The empirical results so far are mixed. While many studies support a significant relationship between migration and climatic factors such as natural disasters, temperature, and precipitation (Reuveny and Moore, 2009; Feng et al., 2010; Marchiori et al., 2012; Gray and Muller, 2012; Feng and Oppenheimer, 2012, Bohra-Mishra et al., 2014), some researchers find climate to be an inconsequential factor compared to other drivers of migration (Mortreux and Barnett, 2009; Naud, 2010). The apparent inconsistencies among the outcomes of various studies arise partly because such studies are mostly context-specific. They differ in the geographic regions covered and the time frames of study. The effects of climate on human migration are likely to be heterogeneous across time and space, as climate may interact with regionspecific factors, such as other environmental and socio-economic conditions, cultural and lifestyle characteristics, and social networks (Black et al., 2011).

To move this literature forward and gain a more complete picture of the climatemigration relationship, one can either continue to accumulate such context-specific evidence or conduct the analysis at a more aggregate level and focus on the most important linkage(s). This paper takes the second approach, and considers agriculture to be a possible intermediate link between climate and (international) migration. We do so for the following reasons. 
First, a large body of literature has already established a significant sensitivity of crop yields to climatic changes, especially temperature increases (Lobell et al., 2008; Schlenker and Roberts, 2009; Lobell et al., 2011). In particular, recent studies such as Schlenker and Roberts (2009) find extreme heat to be particularly harmful for crop yields. Second, agriculture is an important economic sector in many countries, especially in the developing world, where a large proportion of the population still directly depends on agriculture for a living. Thus it is a plausible hypothesis that agriculture plays an important role in the climate-migration relationship.

In this paper, we use a comprehensive bilateral annual migration dataset covering 163 origin countries and 42 destination countries over the period of 1980-2010 to study the climate-migration relationship empirically. We first estimate a reduced-form model that links origin country weather variations to its international outmigration, while controlling for an important migration determinant - income (approximated by GDP per capita) - as well as unobserved time-invariant country-pair factors and country-specific time trends. To investigate the role of agriculture, interaction terms between weather and agricultural dependence are included in the model. ${ }^{1}$ We find that the effect of temperature on outmigration is positive and statistically significant only for the agriculture-dependent countries.

We then provide some additional pieces of supplementary evidence to show the role played by agriculture in the observed weather-migration relationship. First, we show that the temperature effects on migration are nonlinear and match up with the nonlinear yieldtemperature relationship documented in the literature. Extreme heat is correlated both with lower crop yields and higher outmigration flows. Second, as agricultural countries are usually also low-latitude hot countries and tend to be poor, we interact temperature with latitude and GDP, respectively, to rule out the possible "hot" effect and "poor" effect. Lastly, we show that the GDP of agricultural countries are more negatively affected by higher temperature than non-agricultural countries and in a nonlinear fashion, which also provides

\footnotetext{
${ }^{1}$ Agricultural dependence is a dummy variable, where the top $25 \%$ agriculture-dependent countries (in terms of the share of agricultural value-added in GDP) are assigned with a value of 1 , and the remaining countries are assigned with a value of 0 .
} 
indirect evidence on the importance of the role of the agricultural channel.

Although it is impossible to completely dismiss the possible roles played by many other factors, such as health shocks (Deschenes and Moretti, 2009), violence and conflict (Jacob et al., 2007; Hsiang et al., 2011), and institutions (Dell et al., 2012), our results do suggest that, globally, agriculture is an important intermediate link between climate/weather and international migration. It should be noted that this paper focuses on the sensitivity of international migration to annual variations in temperature. The relationship between future climate/weather variability and migration may change due to shifts in the demographic, economic, and social context as well as many uncertainties. Nevertheless, we believe historical evidence provides insights on possible future climate-driven migration and informs current policy discussions.

The rest of the paper proceeds as follows. The next section reviews the existing literature on climate-induced migration. We then introduce the data and present our empirical strategy, followed by the empirical results. The final section concludes with a brief policy discussions. Details about the data sources are included in the appendix.

\section{Literature Review}

There is a large literature on the determinants of human migration that encompasses several disciplines. Income maximization is usually considered to be one of the most important migration determinants (Roy, 1951; Borjas, 1989; Clark et al., 2007; Mayda, 2010). Simply put, a potential migrant is assumed to compare the income difference between origin and several destinations and the cost of migration, and select a destination which maximizes income. The income maximization framework can be extended to utility maximization in order to incorporate non-pecuniary determinants of migration (Borjas, 1989), such as cultural and linguistic distance, political pressures, conflicts and wars, networks of family and friends, educational and social benefits, immigration policies, subjective well-beings, and amenities (Massey et al., 1993; Borjas, 1999; Clark et al., 2007; Pedersen et al., 2008; Mayda, 2010; Ortega and Peri, 2013; Cai et al., 2014; Adsera and Pytlikova, 2015.). 
During recent decades, the migration literature has paid more and more attention to climatic and environmental factors, such as sea level rise, environmental degradation, weather-related crop failures, and extreme weather events (Hugo, 1996; Myers, 2002; Warner et al., 2009; Piguet et al., 2011; Foresight, 2011; Gray and Mueller, 2012). Many studies found a significant influence of climate on human migration. Using unbalanced panel data, Barrios et al. (2006) found that rainfall affects rural-to-urban migration in sub-Saharan Africa. Feng et al. (2010) and Feng and Oppenheimer (2012) used a Mexican state-level panel data of migration flows, and found a significant semi-elasticity of migration from Mexico to the United States with respect to climate-driven changes in crop yields. Gray and Mueller (2012) showed that crop failures driven by rainfall deficits have a strong effect on mobility in Bangladesh, while flooding has a modest effect. Using a country-level panel data of sub-Saharan Africa, Marchiori et al. (2012) found that weather anomalies have increased internal and international migration through both amenity and economic channels. Mueller et al. (2014) found that flooding has modest impact on migration, while heat stress increases the long-term migration in Pakistan. By following province-to-province movement of more than 7,000 households in Indonesia over a decade and a half, Bohra-Mishra et al. (2014) found that an increase in temperature and, to a lesser extent, variations in rainfall are likely to have a greater effect on permanent outmigration of households than natural disasters.

In contrast, some other studies have not found a significant role for climate. Based on a survey conducted in Tuvalu, Mortreux and Barnett (2009) showed that the vast majority of potential migrants do not consider climate change as a possible reason for leaving the country. Naudé (2010) also reported that natural disasters do not have significant effects on international migration across sub-Saharan African countries. However, these studies did not consider possible indirect impact of climate through income differences and other channels. For example, in the survey data used by Mortreux and Barnett (2009), migrants might not be aware of the possibility that climate change implicitly contributes to socio-economic shocks which directly affect migration, and thus do not cite climate change as a reason to leave when interviewed. While discussing the insignificant effects of natural disasters on 
migration, Naudé (2010) also acknowledged that natural disasters may affect conflict and job opportunities and, as such, have an indirect impact on migration.

Due to data limitations, previous studies on the determinants of migration usually relied on analyses of migrants moving from one origin to one destination (Massey and Espinosa, 1997; Feng et al., 2010) or multiple destinations (Hanson and McIntosh, 2010), or from multiple origins to one destination (Clark et al., 2007; Vogler and Rotte, 2000). More recently, researchers have begun to rely on multi-country bilateral migration data, which not only increase the sample size but also allow controlling for country-pair specific factors through the fixed effects model and facilitates drawing more general conclusions (Pedersen et al., 2008; Mayda, 2010; Ortega and Peri, 2013; Adsera and Pytlikova, 2015). Nevertheless, its application in the climate-migration studies remains limited. Reuveny and Moore (2009) used cross-sectional data of bilateral international migration flows to 15 OECD destination countries in the late 1980s and 1990s to investigate the effects of environmental degradation, e.g., arising from weather-related natural disasters. Beine and Parsons (2015) used a panel of bilateral migration for the period of 1960-2000 to study the impact of climatic change. Their dataset has only five panels of foreign population stock data based on the last five completed censuses. Thus their migration flow data are approximated by the change in migration stocks between census years.

Compared to the existing literature, we use a unique international migration dataset that includes many more origin and destination countries, and lasts for 31 years at the annual frequency. This rich data set, further supplemented by detailed climate information, allows us to investigate the heterogeneities among different country pairs. In particular, we are able to control for various confounding factors through country-pair fixed effects and long run time trends to study the mechanisms underlying the climate-migration relationship. We show that agriculture is an important channel as the temperature-outmigration relationship is only observed in the more agricultural-dependent countries, and in a nonlinear fashion consistent with the nonlinear temperature-agriculture relationship. 


\section{Data and Empirical Model}

\subsection{Data and summary statistics}

We use a unique dataset on bilateral international migration flows and stocks of foreigners in 42 destination countries (mostly OECD countries) from 163 origin countries during the period of $1980-2010 .^{2}$ It was collected by writing mainly to the selected national statistical offices of destination countries to request detailed information on immigration flows and foreign population stocks in their respective countries, sorted by origin country. Although our dataset represents substantial progress over similar datasets used in past research (Pedersen et al., 2008; Mayda, 2010; Ortega and Peri, 2013; Adsera and Pytlikova, 2015), it is not without limitations. First, the dataset is unbalanced, with missing migration flows and stocks for some countries in some years. However, missing observations become less of a problem for more recent years (Table A1). Second, as in the other existing datasets (Ortega and Peri, 2013), different countries use different definitions of an immigrant (Table A2). Nevertheless, by using country-pair fixed effects, we only explore variations over time within each country pair. As changes over time in data quality are unlikely to be correlated with weather patterns, these data limitations should be less of a concern in our analyses.

Cereal yields and the share of agriculture value added in GDP were collected from the World Bank (http://databank.worldbank.org). Yields are measured as kilograms per hectare of harvested land, includes wheat, rice, maize, barley, oats, rye, millet, sorghum, buckwheat, and mixed grains. The purchasing power parity converted GDP Per Capita at 2005 constant prices was obtained from the Penn World Tables version 7.0 (Heston et al.,2011).

Global gridded monthly mean temperature and total precipitation data from 1980 to 2010 were collected from NASA Modern Era Retrospective Analysis for Research and Applications (Rienecker et al., 2011) with a resolution of $2 / 3$ degrees in longitude and $1 / 2$

\footnotetext{
${ }^{2}$ The dataset draws on a migration dataset by Pedersen et al. (2008), covering 22 OECD destination countries and 129 origin countries during the period of 1989-2000. The database has been extended to cover 30 OECD destination countries during the period of 1980-2010 (Adsera and Pytlikova, 2015). The dataset used in our study extends the number of destinations to 42 . These 42 destination countries are also among the 163 origin countries.
} 
degrees in latitude, and then aggregated to be country-level population-weighted, so that the weather conditions for populated regions within a country are given more weight. In addition, we also constructed a measure of growing season exposed time for both between 10 and 30 degrees Celsius and above 30 degrees Celsius using global gridded hourly temperature data, which we will describe in more detail in section 4.2.1.

The total number of observations (in country-pairs) is 95,712 during the period of 1980-2010. On average, for an origin country, about 1,077 people migrate to another specific country during a specific year. During the period of 1980-2010, there were in total about 108 million people migrating to another country; among them, about 85 million (50 million) people migrated through the top $5 \%$ (1\%) country pairs with the largest migration flows. Table 1 presents detailed summary statistics. We observe that less agricultural-dependent countries, measured using share of agricultural value added in GDP, have higher outmigration rates. GDP per capita and cereal yields are lower for more agricultural-dependent countries. In addition, more agricultural-dependent countries tend to have higher temperatures as they are more likely to be located in lower latitude regions, and also have had more rainfalls.

\subsection{Empirical model}

To investigate the role of agriculture in the weather-migration relationship, we estimate the following country-pair fixed-effects regression model:

$$
\begin{aligned}
\ln M_{i j t}= & \beta_{0}+\beta_{1} T M P_{i t}+\beta_{2} P C P_{i t}+\delta_{1} T M P_{i t} * A_{i}+\delta_{2} P C P_{i t} * A_{i} \\
& +\phi x_{i t-1}+\varphi z_{j t-1}+\theta_{i j}+d_{i} \text { year }_{t}+d_{j} \text { year }_{t}+\varepsilon_{i j t}
\end{aligned}
$$

where $M_{i j t}$ denotes the natural logarithm of migration rate, ${ }^{3}$ i.e., migration flow from origin country $i$ to destination country $j$ divided by the population of the origin country $i$ at year t. $T M P_{i t}$ represents the population-weighted annual average of monthly mean temperature in the origin country $i$ in degree Celsius. ${ }^{4} P C P_{i t}$ represents the population-weighted annual

\footnotetext{
${ }^{3}$ We add one to all migration flows before calculating migration rates in order to deal with the issue of zero flows, and then take the natural logarithm of migration rate as the dependent variable.

${ }^{4}$ We use annual average temperature and precipitation data as our main specification but will also try nonlinear measures following Schlenker and Roberts (2009).
} 
average of monthly total precipitation in the origin country $i$ in millimeters. $A_{i}$ is a dummy variable that equals 1 if the origin country $i$ is defined as agriculture-dependent, 0 otherwise. ${ }^{5} x_{i t-1}$ and $z_{j t-1}$ are other control variables specific to origin country $i$ and destination country $j$, respectively, such as the natural logarithm of GDP per capita, which are commonly accepted as an important determinant of migration. The lagged values of GDP per capita are employed to address possible reverse causality that migration flow affects destination countries income (Mayda, 2010). $\theta_{i j}$ denotes country-pair fixed effects, which capture time-invariant unobserved characteristics between two specific countries, such as distance, historical and cultural ties, linguistic distance, and many more. Using country-pair fixed effects, we only explore the variations over time within each country pair. To the extent that these country-pair unobserved factors are correlated with weather conditions in origin countries, an alternative model using only origin-country fixed effects would be misspecified. $d_{i}$ year $_{t}$ and $d_{j}$ year $_{t}$ denote origin and destination country-specific linear time trends, which control for factors evolving over time within specific countries, such as urbanization, employment possibilities, welfare schemes, migrant networks and immigration policy schemes. $\varepsilon_{i j t}$ denotes the error term. In our empirical work, we always report robust standard errors clustered at the origin country level as identification of temperature effects mainly comes from variations at the country-year level. ${ }^{6} \quad \beta_{0}, \beta_{1}, \beta_{2}, \delta_{1}, \delta_{2}, \phi$ and $\varphi$ are parameters to be estimated. The key parameters of interest are $\delta_{1}$ and $\delta_{2}$, which capture the differential weather effects in agriculture-dependent countries versus the other countries.

\footnotetext{
${ }^{5}$ In the basic specification, we denote agricultural countries as those whose agricultural value-added as a share of GDP is among the top $25 \%$ of all countries. We have also tried $33 \%$ and $20 \%$ as robustness checks and the results are qualitatively similar.

${ }^{6}$ We also calculate standard errors clustered at the country-pair level as a robustness check.
} 


\section{Results}

\subsection{Main results: the role of agriculture in the weather-migration relationship}

Table 2 presents our main results. In column (1), we regress the natural logarithm of migration rate on contemporaneous temperature and precipitation of the origin countries. In column (2) of Table 2, the interaction terms between weather and agricultural dependence are included to test if the weather effects are different between the top $25 \%$ agriculturedependent countries and the remaining ones. In the last column of Table 2, which is our preferred specification as stated in Equation (1), we further include the natural logarithm of lagged GDP per capita for both origin and destination countries. All three models contain a set of country-pair fixed effects and the origin and destination country-specific linear time trends. A positive and significant coefficient estimate for the interaction term suggests that the temperature effects are significantly different between agricultural and non-agricultural countries, and more likely to induce significant outmigration from agricultural countries. Specifically, based on results in column (3) of Table 2 , each $1^{\circ} \mathrm{C}$ increase in temperature implies a $5 \%$ increase in outmigration from the top $25 \%$ agricultural countries (significant at the $1 \%$ level), as compared to only $0.4 \%$ increase (statistically insignificant) in outmigration from the remaining countries. This is in line with Marchiori et al. (2012) who also found that weather changes in agricultural countries induce outmigration. As shown in the last two columns of Table 2, the results are rather robust and hold with or without controlling for the natural logarithm of lagged GDP per capita.

In Table 3, we present a number of robustness checks for the coefficient of the interaction term between temperature and agricultural dependence. Our main results are qualitatively the same whether we use different control variables (Panel B), different dependent or key independent variables (Panel C), different regression techniques (Panel D), or slightly different samples (Panel E). When conducting the robustness checks, we also allow different thresholds for the definition of agricultural countries in the first three columns of 
Table 3) - the top one-third (33\%), top one-fourth (25\%), and top one-fifth (20\%) countries in terms of the share of agriculture value added in GDP. In general, the differential temperature effects for agricultural countries become larger in magnitude and more statistically significant when a higher threshold is set to identify agricultural countries. Further, in column (4) of Table 3, we use a continuous measure of agricultural-dependency, which is the percentage of agricultural value-added in GDP. ${ }^{7}$ Overall, the results are consistent with the idea that more agriculture-dependent countries are more likely to experience outmigration when temperature rises. We discuss those robustness check results in more details below.

We first report results with different sets of control variables. The contemporaneous temperature effects become slightly weaker but still significant when the lagged temperature and precipitation up to five years are also included in the model (Panels B1 and B2). This implies that temperature may have some lagged effects on outmigration as it takes time to stimulate some of international migration flows. Migration flows may be largely determined by the existing co-ethnic networks, i.e. networks of family members, friends and people of the same origin that have already lived in a host country (Munshi, 2003; Pedersen et al., 2008). In Panel B3, we control for migration stock (foreign population from country $i$ residing in country $j$ ) as a proxy for migrant networks and find that our results still hold. Since the migration rate may be serially correlated, we also use the lagged dependent variable - the natural logarithm of lagged one-year migration rate as one of the independent variables (Panel B4). The estimates are still significant but smaller in magnitude, as would be expected in this kind of dynamic models. In Panel B5, the temperature effects are still positive and significant when we include an origin country-specific quadratic time trend, which controls for some nonlinear determinants of migration trend over time for each origin country.

We used the country-pair fixed effects in the baseline specification, while two separate country fixed effects - one for origin and the other for destination countries - were chosen as the baseline specification in some other studies (Mayda, 2010; Ortega and Peri, 2013).

\footnotetext{
${ }^{7}$ We also tried to slice the sample into four equally divided subgroups by percentage of agricultural valueadded in GDP. The results are reported in Appendix Table A3. In general, we find that the temperature effect on outmigration is only significant in the most agricultural-dependent countries, consistent with results reported in Table 2 and Table 3.
} 
In Panel B6, we control for the separate country fixed effects and other variables such as the distance between the most populated city in the source country and the most populated city in the destination country, common language, colonial tie, and common border which were not included in the model with country-pair fixed effects as they would be absorbed by country-pair fixed effects (Ortega and Peri, 2013; Adsera and Pytlikova, 2015). With this alternative specification, the temperature effects are still positive and significant for all definitions of agriculture-dependent countries. The magnitudes of the coefficients are even larger than in the baseline specification. This suggests that many country-pair specific factors may not have been adequately controlled for when only (origin and destination) country fixed effects are included.

Panel B7 includes year fixed effects and their interactions with country baseline characteristics (GDP per capita at the year 1980). This specification allows the time trend to be flexible enough while permitting countries with different initial characteristics, such as GDP per capita, to have different trends over time. Again, the results are consistent with the baseline ones qualitatively. In Panel B8, we also control for the weather in destination countries. We find that destination countries' weather conditions are not significant determinants of international migration. The coefficients of the interaction term between temperature in origin countries and agricultural dependence are almost the same as in the baseline specification.

We further use the natural logarithm of migration flows (Panel C1), instead of the natural logarithm of migration rate, as the dependent variable. The results are very similar to the baseline specification. In Panel C2, instead of estimating the contemporaneous temperature effects, we estimate the lagged temperature effects, and find a slightly smaller lagged response of migration flow to temperature, which is consistent with our expectation based on Panels B1 and B2.

In Panel D1, we run a weighted least squares regression using the natural logarithm of the origin country's population as weight, which does not change our baseline results. This specification essentially gives more weight to larger countries, therefore reduces the effects of 
possible large changes in migration rate from small countries with low levels of outmigration. Panel D2 reports the standard errors clustered at the country-pair level, rather than at the origin country level as in the baseline specification. The significance levels of our main coefficients are not affected much.

Finally, we also study if the main results are driven by some outlier countries or country pairs. During the past three decades, 85 million (50 million) out of 108 million migrants are in the top 5\% (1\%) migration routes (from one country to another) by the size of migration flow. We remove the data from the top 5\% (1\%) migration routes in Panel E1 (Panel E2). In addition, as about $11 \%$ of all the country pairs do not have any migration flows, we drop those zero migration flows from the sample in Panel E3. In both cases, the coefficient estimates for the interaction term remain positive and statistically significant.

Following the literature, we include both temperature and precipitation variables in the baseline specification. We do not interpret the precipitation coefficients here, since statistical methods appear more reliable for temperature variables (Lobell and Burke, 2010); this may be explained by the fact that precipitation has higher spatial variability and thus is less well captured than temperature by the relatively coarse climate data (Burke et al., 2009), e.g., country-level in our study. However, it is still necessary to control for precipitation in our model since it is a possible confounding factor, which may be correlated with both temperature (independent variable) and migration (dependent variable).

We further study the role of different destination countries in climate-induced migration. In Table 4, we divide our dataset into four parts by the popularity of destination countries (based on migration stock) for each origin country. In other words, each of these four sub-datasets includes all 163 origin countries, but only a quarter of destination countries. We find that our main results - positive temperature effects on outmigration from agricultural countries - are only detected in the migration routes to their top $25 \%$ migration destination countries (Table 4, column 4). The results imply that temperature tends to intensify migration mostly in the already established migration routes for agricultural countries, while it has insignificant effect on migration to the countries which are previously 
not major destinations. This finding is in line with previous hypotheses that climate change will intensify existing migration routes (McLeman and Hunter, 2010; World Bank, 2010).

\subsection{Additional results: Is it truly the agricultural channel?}

In the previous subsection, we have shown that the weather-migration relationship, notably the temperature-migration relationship, differs significantly for agricultural countries and non-agricultural countries. The results are not only robust to different empirical specifications, as we have painstakingly shown, but also consistent with the vast literature on the

detrimental role of high temperature on agricultural productivity. Nevertheless, although highly unlikely, it is still possible that the level of agricultural dependence in a country is merely a proxy for something else that truly drives the temperature-migration relationship. To further rule out such possibilities, we do three things in this subsection.

First, we show that weather effects on migration are nonlinear and in a way consistent with the nonlinear yield-temperature relationship documented in the literature (Schlenker and Roberts, 2009). Specifically, extreme heat in growing seasons is detrimental to crops and induces outmigration. Second, we rule out the possible confounding "hot" effect and "poor" effect by including directly interaction terms of temperature with latitude and GDP, respectively. As discussed in Dell et al. (2012), agricultural countries are usually also lowlatitude hot countries, and tend to be poor. Lastly, we show that the GDP of agricultural countries is more negatively affected by higher temperature than non-agricultural countries, and in a nonlinear fashion. This provides indirect evidence on the importance of the role of the agricultural channel as GDP is a major determinant of international migration. None of these results individually prove that agriculture is the main channel behind the temperature-migration relationship that we report in this paper, but they collectively do offer corroborative, if not definitive, evidence for our main hypothesis.

\subsubsection{Nonlinear effects of temperature on outmigration}

The recent literature on the relationship between agriculture yields and temperature suggests that it is highly nonlinear (Schlenker and Roberts, 2009). If agriculture is indeed the main channel behind the observed temperature-migration relationship, then we would 
expect it also to be nonlinear.

To investigate this, we first calculate a nonlinear temperature measure that records total exposure time to a given interval of temperature during the growing season following Schlenker and Roberts, using global gridded hourly temperature data from NASA-Modern Era Retrospective Analysis for Research and Applications (Rienecker et al., 2011). We also use Crop Calendar Dataset ${ }^{8}$ to determine the growing seasons for each grid cell. The data contain starting and ending dates of the planting season and the harvesting season for 19 different types of crops. To ensure comparability, we selected five major crops from the list: rice, wheat, soybeans, maize and potato. For each grid cell defined globally, we aggregate all daily exposures to the whole growing season by crop. ${ }^{9}$ Following Schlenker and Roberts (2009), we use $30^{\circ} \mathrm{C}$ as the cut-off for extreme heat and measure total number of hours exposed to such temperature above $30^{\circ} \mathrm{C}$ during the growing season. ${ }^{10}$ We also calculate growing season total exposure hours to temperatures between $10^{\circ} \mathrm{C}$ and $30^{\circ} \mathrm{C}$, as temperatures below $10^{\circ} \mathrm{C}$ are usually not useful for crop growth. We then take averages of the five major crops. The two exposure variables are first constructed at the grid-level for each year, and then aggregated to the country level using the year 2000 population as weights.

The regression equation is as follows,

$$
\begin{aligned}
\ln M_{i j t}= & \beta_{0}+\beta_{1} G 1030_{i t}+\beta_{2} G 30_{i t}+\beta_{3} P C P_{i t}+\delta_{1} G 1030_{i t} * A_{i}+\delta_{2} G 30_{i t} * A_{i} \\
& +\delta_{3} P C P_{i t} * A_{i}+\phi x_{i t-1}+\varphi z_{j t-1}+\theta_{i j}+d_{i} \text { year }_{t}+d_{j} \text { year }_{t}+\varepsilon_{i j t}
\end{aligned}
$$

where $G 1030_{i t}$ and $G 30_{i t}$ are growing season exposure to temperatures between $10-30^{\circ} \mathrm{C}$ and above $30^{\circ} \mathrm{C}$, respectively.

Table 5 reports nonlinear temperature effects on outmigration. Again, we expect this

\footnotetext{
${ }^{8}$ website: https://nelson.wisc.edu/sage/data-and-models/crop-calendar-dataset/index.php

${ }^{9}$ We use the middle day of the planting season as the start of a growing season and the middle day of the harvesting season as the end of a growing season.

${ }^{10}$ Using U.S. data, Schlenker and Roberts (2009) find that crop yield growth increases gradually with temperature up to $29-32^{\circ} \mathrm{C}$ depending on the crop, and then decreases sharply once the cutoff is surpassed. We use $30^{\circ} \mathrm{C}$ as the cutoff for extreme heat but the results are robust to reasonable changes in the cutoff.
} 
effect to be mainly for agriculture countries so the interaction terms are included. Indeed, we find that exposure to extreme heat induces outmigration, but only in agricultural countries. In column (2), the coefficient for the interaction term between agriculture and extreme heat exposure is 0.05 , which means that an additional 100 hours of exposure to $30^{\circ} \mathrm{C}+$ weather during the growing season would raise outmigration rate by 5 percentage points. When source country GDP is also controlled for (Column 3 of Table 5), this effect declined slightly to 3.5 percentage points but remains statistically significant at the $10 \%$ level. For non-agricultural countries, the effect is essentially zero.

To directly compare, Table 6 reports temperature effects on cereal yields, using a panel of 158 countries spanning the period under our study. In columns (1) and (2), we find that higher mean temperatures are associated with lower cereal yields. Consistent with Schlenker and Roberts (2009) and other studies, we also find nonlinear temperature effects in columns (3) and (4). The detrimental effect of extreme heat exposure on cereal yield is both large in magnitude and highly statistically significant in our sample. The effects are robust whether we control for source country GDP or not. Therefore, the nonlinear relationship between temperature and yields resembles that between temperature and outmigration.

\subsubsection{Adding latitude-temperature and GDP-temperature interactions}

A country's agricultural dependence is likely to be correlated with many other characteristics. As discussed in Dell et al. (2012), many agricultural countries are in relatively hot low-latitude regions, and they are more likely to be poor countries. To make sure that our main results do not merely capture the "hot" effect or "poor" effect, we directly control for the temperature-latitude and temperature-GDP interactions in the regressions.

Table 7 shows the results. In column (3), when both the latitude-temperature and agriculture-temperature interactions are included in the regression, the latitude-temperature term is not significant, and the agriculture-temperature term becomes slightly larger in magnitude and remains highly significant. Overall, it shows that agriculture rather than location per se is a significant mediator of the temperature-migration relationship. This helps to rule out many alternative channels. For example, it is unlikely that some mosquito- 
borne diseases, which are more prevalent in low-latitude countries, have been driven the more significant temperature-migration relationship in agricultural countries.

Next we include the GDP-temperature interaction terms. In Column (4) we find that the GDP-temperature interaction term to be positive and significant when included without the agriculture-temperature term. In Column (5), we include the GDP-temperature term together with the agriculture-temperature term, and column (6) further includes squared term of GDP interacted with temperature to capture possible nonlinearity. In both cases, we find that the agriculture-temperature term remains positive and statistically significant. On the other hand, sensitivity to temperature in terms of outmigration displays some nonlinearity, as shown in Column (6) of Table 7. Outmigration in both very poor countries and very rich countries are less sensitive to temperature variations than those in the middle. For very poor countries, migration to foreign countries may not be a viable option for most people due to the so called "poverty trap" (Clark et al, 2007 and Pedersen et al., 2008). For rich developed countries, it is unlikely that temperature play a major role in outmigration decisions, as the agricultural channel we highlight in this paper becomes almost irrelevant. The agricultural sector in those countries are usually small, and farmers may be able to find employment opportunities in domestic nonfarm sectors relatively easily even in times of difficulty.

\subsubsection{Impact of weather on GDP for agricultural/non-agricultural countries}

Next we investigate the relationship between GDP and weather variables for agricultural and non-agricultural countries. The regressions use natural logarithm of GDP per capita as the dependent variable, where the main independent variable is the interaction term between agricultural dependence and temperature. In Table 8, the first two columns use average temperature. While all specifications include the country fixed effects, column (1) includes a linear time trend for all countries, while column (2) includes time dummies

for each year. Across all specifications, the coefficients of the interaction terms are negative and significant. Therefore, higher temperature reduces GDP for agricultural countries more than non-agricultural countries. In columns (3)-(4), we use the nonlinear temperature measures. We find that extreme heat over $30^{\circ} \mathrm{C}$ significantly reduce GDP of agricultural 
countries but not the non-agricultural ones. The interaction term of exposure time between $10^{\circ} \mathrm{C}$ and $30^{\circ} \mathrm{C}$ and agriculture are not significant. Because GDP is a main determinant of international migration, the results here, particularly the nonlinear relationship between GDP and temperature in agricultural countries, provide an indirect evidence for the agricultural linkage between temperature and migration.

The results reported here are also consistent with the literature. Dell et al. (2012) used more than 50 years' time series data to empirically investigate how temperature changes are related to GDP, and they found that higher temperature only negatively impacts GDP of poor countries. They also listed agriculture as an important explanation of this relationship, and provided evidence on the negative relationship between temperature and agricultural value-added. Nevertheless, they have not explored the nonlinear temperature effect on GDP as we do here due to limitations on their data sources. They also do not directly link temperature to migration as it is beyond the scope of their study.

\section{Conclusions}

This study empirically investigates the effects of weather variations on global international migration flows using a rich bilateral annual panel data for years 1980-2010. The results show that temperature has a positive and statistically significant effect on outmigration, but only for agriculture-dependent countries. Further, the temperature-migration relationship is nonlinear and resembles the nonlinear temperature-yield relationship. In particular, extreme heat is bad for agricultural productivity and induces international outmigration. Therefore, among the intermediate links between weather and international migration, agriculture appears to be an important one. Our results are robust to alternative model specifications.

While our results suggest that significant climate-induced international outmigration only happens in agriculture-dependent countries, the consequences may be substantial. We further find that climate-induced migration specifically enlarges the flow in already established migration routes, potentially presenting challenges to major migrant-receiving coun- 
tries, mostly industrialized. Studies such as this one could provide a basis for industrialized countries to consider policies to address the consequences (both positive and negative) of potential increases in migration due to climate change. Our results also provide some guidance to those developing policies to anticipate and manage these flows by focusing attention on agricultural countries and especially people in those countries whose livelihoods depend on agriculture. Agricultural adaptation, which builds resilience and enhances farmers' earnings capacities, may reduce incentives to migrate. Diversifying livelihoods for those who now depend on agriculture, such as by encouraging off-farm work, urbanization or structural upgrading, also has the potential to reduce migration.

Although this study provides robust empirical evidence that agriculture is an important factor influencing climate-induced international migration based on a comprehensive international migration dataset over the past three decades, future research should further test our results as additional migration and climate/weather data becomes available. While we perform the analysis using the statistical approach, alternative methods and tools, such as ethnographic studies, should also be used to study these relationships where appropriate. In addition, other possible intermediaries, such as health shocks and civil conflicts, should also be investigated in order to have a fuller understanding of the climate/weather-migration relationship. 


\section{References}

Alicia Adsera and Mariola Pytlikova. The role of language in shaping international migration. The Economic Journal, 125(586):49-81, 2015.

Salvador Barrios, Luisito Bertinelli, and Eric Strobl. Climatic change and rural-urban migration: The case of sub-Saharan Africa. Journal of Urban Economics, 60(3):357-371, 2006.

Michel Beine and Christopher Parsons. Climatic factors as determinants of international migration. The Scandinavian Journal of Economics, 117:723C767, 2015.

Richard Black, Dominic Kniveton, and Kerstin Schmidt-Verkerk. Migration and climate change: towards an integrated assessment of sensitivity. Environment and Planning A, 43:431-450, 2011.

Pratikshya Bohra-Mishra, Michael Oppenheimer, and Solomon M. Hsiang. Nonlinear permanent migration response to climatic variations but minimal response to disasters. Proceedings of the National Academy of Sciences, 111(27):9780-9785, 2014.

George J Borjas. Economic theory and international migration. International migration review, 23(3):457-485, 1989.

George J Borjas. The economic analysis of immigration. In Orley Ashenfelter and David Card, editors, Handbook of labor economics, volume 3, pages 1697-1760. Elsevier, 1999.

Marshall B Burke, Edward Miguel, Shanker Satyanath, John A Dykema, and David B Lobell. Warming increases the risk of civil war in Africa. Proceedings of the National Academy of Sciences, 106(49):20670-20674, 2009.

Ruohong Cai, Neli Esipova, Michael Oppenheimer, and Shuaizhang Feng. International migration desires related to subjective well-being. IZA Journal of Migration, 3(1):1-20, 2014. 
Ximena Clark, Timothy J Hatton, and Jeffrey G Williamson. Explaining US immigration, 1971-1998. The Review of Economics and Statistics, 89(2):359-373, 2007.

Melissa Dell, Benjamin F Jones, and Benjamin A Olken. Temperature shocks and economic growth: Evidence from the last half century. American Economic Journal: Macroeconomics, 4(3):66-95, 2012.

Olivier Deschenes and Enrico Moretti. Extreme weather events, mortality, and migration. The Review of Economics and Statistics, 91(4):659-681, 2009.

Shuaizhang Feng and Michael Oppenheimer. Applying statistical models to the climatemigration relationship. Proceedings of the National Academy of Sciences, 109(43):2915$2915,2012$.

Shuaizhang Feng, Alan B Krueger, and Michael Oppenheimer. Linkages among climate change, crop yields and Mexico-US cross-border migration. Proceedings of the National Academy of Sciences, 107(32):14257-14262, 2010.

Shuaizhang Feng, Michael Oppenheimer, and Wolfram Schlenker. Climate change, crop yields, and internal migration in the United States. NBER Working paper W17734, National Bureau of Economic Research, 2012.

Foresight. Migration and global environmental change: Future challenges and opportunities. The Government Office for Science, UK, 2011.

Clark L Gray and Valerie Mueller. Natural disasters and population mobility in Bangladesh. Proceedings of the National Academy of Sciences, 109(16):6000-6005, 2012.

Gordon H Hanson and Craig McIntosh. The great Mexican emigration. The Review of Economics and Statistics, 92(4):798-810, 2010.

Alan Heston, Robert Summers, and Bettina Aten. Penn World Table Version 7.0. Center for International Comparisons of Production, Income and Prices at the University of Pennsylvania, 2011. 
Solomon M Hsiang, Kyle C Meng, and Mark A Cane. Civil conflicts are associated with the global climate. Nature, 476(7361):438-441, 2011.

Graeme Hugo. Environmental concerns and international migration. International Migration Review, 30(1):105-131, 1996.

IPCC. Climate change 2014: Synthesis Report. Contribution of Working Groups I, II and III to the Fifth Assessment Report of the Intergovernmental Panel on Climate Change, 2014.

Brian Jacob, Lars Lefgren, and Enrico Moretti. The dynamics of criminal behavior evidence from weather shocks. Journal of Human Resources, 42(3):489-527, 2007.

David B Lobell and Marshall B Burke. On the use of statistical models to predict crop yield responses to climate change. Agricultural and Forest Meteorology, 150(11):1443-1452, 2010.

David B Lobell, Marshall B Burke, Claudia Tebaldi, Michael D Mastrandrea, Walter P Falcon, and Rosamond L Naylor. Prioritizing climate change adaptation needs for food security in 2030. Science, 319(5863):607-610, 2008.

David B Lobell, Wolfram Schlenker, and Justin Costa-Roberts. Climate trends and global crop production since 1980. Science, 333(6042):616-620, 2011.

Luca Marchiori, Jean-François Maystadt, and Ingmar Schumacher. The impact of weather anomalies on migration in sub-Saharan Africa. Journal of Environmental Economics and Management, 63(3):355-374, 2012.

Douglas S Massey and Kristin E Espinosa. What's driving Mexico-US migration? A theoretical, empirical, and policy analysis. American Journal of Sociology, 102(4):939-999, 1997. 
Douglas S Massey, Joaquin Arango, Graeme Hugo, Ali Kouaouci, Adela Pellegrino, and J Edward Taylor. Theories of international migration: A review and appraisal. Population and Development Review, 19(3):431-466, 1993.

Anna Maria Mayda. International migration: A panel data analysis of the determinants of bilateral flows. Journal of Population Economics, 23(4):1249-1274, 2010.

Robert A McLeman and Lori M Hunter. Migration in the context of vulnerability and adaptation to climate change: insights from analogues. Wiley Interdisciplinary Reviews: Climate Change, 1(3):450-461, 2010.

Colette Mortreux and Jon Barnett. Climate change, migration and adaptation in Funafuti, Tuvalu. Global Environmental Change, 19(1):105-112, 2009.

Valerie Mueller, Clark Gray, and Katrina Kosec. Heat stress increases long-term human migration in rural Pakistan. Nature Climate Change, 4(3):182-185, 2014.

Banco Mundial. World Development Report 2010: Development and Climate Change. World Bank, 2010.

Kaivan Munshi. Networks in the modern economy: Mexican migrants in the US labor market. Quarterly Journal of Economics, 118(2):549-599, 2003.

Norman Myers. Environmental refugees: a growing phenomenon of the 21st century. Philosophical Transactions of the Royal Society of London B: Biological Sciences, 357(1420): 609-613, 2002.

Wim Naudé. The determinants of migration from Sub-Saharan African countries. Journal of African Economies, 19(3):330-356, 2010.

Francesc Ortega and Giovanni Peri. The effect of income and immigration policies on international migration. Migration Studies, 1(3):1-28, 2013. 
Peder J Pedersen, Mariola Pytlikova, and Nina Smith. Selection and network effects migration flows into OECD countries 1990-2000. European Economic Review, 52(7):1160$1186,2008$.

Etienne Piguet, Antoine Pécoud, and Paul De Guchteneire. Migration and climate change: An overview. Refugee Survey Quarterly, 30(3):1-23, 2011.

Rafael Reuveny and Will H Moore. Does environmental degradation influence migration? emigration to developed countries in the late 1980s and 1990s. Social Science Quarterly, 90(3):461-479, 2009.

Michele M Rienecker, Max J Suarez, Ronald Gelaro, Ricardo Todling, Julio Bacmeister, Emily Liu, Michael G Bosilovich, Siegfried D Schubert, Lawrence Takacs, and Gi-Kong Kim. MERRA: NASA's modern-era retrospective analysis for research and applications. Journal of Climate, 24(14):3624-3648, 2011.

Andrew Donald Roy. Some thoughts on the distribution of earnings. Oxford Economic Papers, 3(2):135-146, 1951.

Wolfram Schlenker and Michael J Roberts. Nonlinear temperature effects indicate severe damages to us crop yields under climate change. Proceedings of the National Academy of sciences, 106(37):15594-15598, 2009.

Nicholas Stern. The economics of climate change: the Stern review. cambridge University press, 2007.

Michael Vogler and Ralph Rotte. The effects of development on migration: Theoretical issues and new empirical evidence. Journal of Population Economics, 13(3):485-508, 2000.

Koko Warner, Charles Ehrhart, A de Sherbinin, Susana Adamo, and Tricia Chai-Onn. In search of shelter: Mapping the effects of climate change on human migration and displacement. CARE International, 2009. 
Table 1: Summary statistics

\begin{tabular}{llllll}
\hline & \multicolumn{3}{l}{ Four equal-sized country groups } & \multicolumn{2}{l}{ All countries } \\
& $(1)$ & $(2)$ & $(3)$ & $(4)$ & $(5)$ \\
\hline Outmigration rate & $0.18 \%$ & $0.30 \%$ & $0.17 \%$ & $0.10 \%$ & $0.19 \%$ \\
& $(0.18 \%)$ & $(0.38 \%)$ & $(0.32 \%)$ & $(0.30 \%)$ & $(0.31 \%)$ \\
GDP per capita (2005 US dollar) & 23438 & 8635 & 3161 & 1222 & 9631 \\
& $(13771)$ & $(6299)$ & $(2233)$ & $(1550)$ & $(12783)$ \\
Cereal yields (Kilogram/Hectare) & 3709 & 2594 & 2013 & 1531 & 2463 \\
Share of agricultural value-added in GDP & $(2076)$ & $(1569)$ & $(1193)$ & $(962)$ & $(1711)$ \\
& $(2.25 \%$ & $10.14 \%$ & $20.48 \%$ & $38.97 \%$ & $18.15 \%$ \\
Monthly mean temperature $\left({ }^{\circ} \mathrm{C}\right)$ & 15.712 & $18.48 \%)$ & $(6.77 \%)$ & $(11.41 \%)$ & $(15.10 \%)$ \\
& $(8.81)$ & $(7.63)$ & $(8.01)$ & $(5.62)$ & $(8.07)$ \\
Monthly total precipitation $($ Millimeters) & 60.195 & 101.828 & 93.276 & 123.821 & 93.578 \\
& $(39.23)$ & $(77.89)$ & $(70.28)$ & $(82.68)$ & $(72.89)$ \\
Growing season exposure $30^{\circ} \mathrm{C}+($ Hours $)$ & 452 & 338 & 538 & 470 & 452 \\
Growing season exposure $10-30^{\circ} \mathrm{C}$ (Hours) & $(617)$ & $(375)$ & $(445)$ & $(420)$ & $(476)$ \\
& $(5631$ & 2839 & 2565 & 2815 & 2684 \\
& $(674)$ & $(640)$ & $(690)$ & $(652)$ \\
\hline
\end{tabular}

Note: Columns (1)-(4) are four country groups divided by the lower quartile, median, and the upper quartile in terms of the share of agriculture value added in GDP, where column (1) represents the least agriculture-dependent countries, and column (4) includes the most agriculture-dependent countries. Column (5) includes all the countries. Standard deviations are in parentheses. 
Table 2: Climate and international migration: the main results

\begin{tabular}{|c|c|c|c|}
\hline & $(1)$ & $(2)$ & (3) \\
\hline Temperature & $\begin{array}{l}0.011^{* *} \\
(0.005)\end{array}$ & $\begin{array}{l}0.003 \\
(0.008)\end{array}$ & $\begin{array}{l}0.004 \\
(0.008)\end{array}$ \\
\hline Temperature x Agriculture & & $\begin{array}{l}0.047^{* * *} \\
(0.018)\end{array}$ & $\begin{array}{l}0.046^{* * *} \\
(0.018)\end{array}$ \\
\hline Precipitation & $\begin{array}{l}0.0003 \\
(0.0003)\end{array}$ & $\begin{array}{l}0.0001 \\
(0.0003)\end{array}$ & $\begin{array}{l}0.0001 \\
(0.0003)\end{array}$ \\
\hline Precipitation x Agriculture & & $\begin{array}{l}0.001 \\
(0.001)\end{array}$ & $\begin{array}{l}0.001 \\
(0.001)\end{array}$ \\
\hline Log of lagged origin GDP per capita & & & $\begin{array}{l}-0.360^{* * *} \\
(0.085)\end{array}$ \\
\hline Log of lagged destination GDP per capita & & & $\begin{array}{l}1.081^{* * *} \\
(0.094)\end{array}$ \\
\hline Country-pair fixed effects & Yes & Yes & Yes \\
\hline Origin and destination country-specific linear time trend & Yes & Yes & Yes \\
\hline Number of Observations & 95,712 & 95,712 & 95,712 \\
\hline Number of origin countries & 163 & 163 & 163 \\
\hline Adjusted $R^{2}$ & 0.9369 & 0.9369 & 0.9374 \\
\hline $\begin{array}{l}\text { Temperature effect in } \\
\text { agriculture-dependent countries }\end{array}$ & & $\begin{array}{l}0.050^{* * *} \\
(0.016)\end{array}$ & $\begin{array}{l}0.050^{* * *} \\
(0.017)\end{array}$ \\
\hline
\end{tabular}

Note: Dependent variable is the natural logarithm of migration rate from origin country $i$ to destination country $j$. Temperature and precipitation variables are measured in country $i$. The dummy variable "Agriculture" in the interaction term is defined where the top $25 \%$ agriculture-dependent countries are assigned with 1 , and the remaining countries are assigned with 0 . Robust standard errors clustered by origin countries are reported in parentheses. $* * *, * *$, and $*$ denote significance at the $1 \%, 5 \%$, and $10 \%$ levels, respectively. 
Table 3: Robustness checks for the main results

\begin{tabular}{|c|c|c|c|}
\hline $\begin{array}{l}\text { Alternative de } \\
\text { (1) Top } 33 \%\end{array}$ & $\begin{array}{l}\text { ions of agricul } \\
\text { (2) Top } 25 \%\end{array}$ & $\begin{array}{l}\text { country } \\
\text { (3) Top } 20 \%\end{array}$ & $\begin{array}{l}\text { (4) Agriculture } \\
\text { as } \% \text { of GDP }\end{array}$ \\
\hline \multicolumn{4}{|l|}{ Panel A: Baseline specification } \\
\hline 0.019 & $0.046^{* * *}$ & $0.055^{* * *}$ & $0.116^{* *}$ \\
\hline$(0.016)$ & $(0.018)$ & $(0.019)$ & $(0.046)$ \\
\hline \multicolumn{4}{|c|}{ Panel B: Different control variables } \\
\hline \multicolumn{4}{|c|}{ B1: Controlling for lagged one year temperature and precipitation } \\
\hline 0.008 & $0.031^{*}$ & $0.042^{* *}$ & 0.068 \\
\hline$(0.014)$ & $(0.017)$ & $(0.019)$ & $(0.045)$ \\
\hline \multicolumn{4}{|c|}{ B2: Controlling for lagged temperature and precipitation up to five years } \\
\hline 0.005 & 0.028 & $0.041^{* *}$ & 0.072 \\
\hline$(0.016)$ & $(0.019)$ & $(0.020)$ & $(0.050)$ \\
\hline \multicolumn{4}{|c|}{ B3: Controlling for the log of lagged migration stock } \\
\hline 0.019 & $0.044^{* *}$ & $0.052^{* * *}$ & $0.117^{* * *}$ \\
\hline$(0.016)$ & $(0.018)$ & $(0.020)$ & $(0.045)$ \\
\hline \multicolumn{4}{|c|}{ B4: Controlling for the log of lagged one year migration rate } \\
\hline 0.013 & $0.025^{*}$ & $0.027^{*}$ & $0.075^{* *}$ \\
\hline$(0.011)$ & $(0.013)$ & $(0.014)$ & $(0.033)$ \\
\hline \multicolumn{4}{|c|}{ B5: Controlling for origin country-specific quadratic time trend } \\
\hline 0.012 & $0.031^{*}$ & $0.043^{* *}$ & $0.086^{*}$ \\
\hline$(0.014)$ & $(0.017)$ & $(0.017)$ & $(0.050)$ \\
\hline \multicolumn{4}{|c|}{ B6: Controlling for both origin and destination country fixed effects } \\
\hline $0.050^{* * *}$ & $0.076 * * *$ & $0.079^{* * *}$ & $0.116^{* *}$ \\
\hline$(0.01)$ & $(0.02)$ & $(0.02)$ & $(0.046)$ \\
\hline \multicolumn{4}{|c|}{ B7: Adding year fixed effects and its interaction with baseline characteristics } \\
\hline 0.010 & 0.029 & $0.037^{*}$ & 0.078 \\
\hline$(0.016)$ & $(0.019)$ & $(0.021)$ & $(0.050)$ \\
\hline \multicolumn{4}{|c|}{ B8: Controlling for destination country weather } \\
\hline 0.019 & $0.045^{* *}$ & $0.054^{* * *}$ & $0.085^{*}$ \\
\hline$(0.016)$ & $(0.018)$ & $(0.020)$ & $(0.045)$ \\
\hline \multicolumn{4}{|c|}{ Panel C: different dependent/independent variables } \\
\hline \multicolumn{4}{|c|}{ C1: Using the natural logarithm of migration flows as dependent variable } \\
\hline 0.020 & $0.046^{* *}$ & $0.053^{* * *}$ & $0.116^{* *}$ \\
\hline$(0.016)$ & $(0.018)$ & $(0.020)$ & $(0.046)$ \\
\hline \multicolumn{4}{|c|}{$\mathrm{C} 2$ : Using lagged temperature and precipitation as independent variable } \\
\hline $0.029^{*}$ & $0.038^{*}$ & $0.037^{*}$ & $0.140^{* *}$ \\
\hline$(0.016)$ & $(0.020)$ & $(0.022)$ & $(0.059)$ \\
\hline \multicolumn{4}{|c|}{ Panel D: different regression techniques } \\
\hline \multicolumn{4}{|c|}{ D1: Regressions weighted by the natural logarithm of origin country population } \\
\hline 0.022 & $0.049 * *$ & $0.057^{* * *}$ & $0.125^{* *}$ \\
\hline$(0.017)$ & $(0.019)$ & $(0.020)$ & $(0.049)$ \\
\hline \multicolumn{4}{|c|}{ D2: Clustering at the country pair level } \\
\hline $0.019 *$ & $0.046^{* * *}$ & $0.055^{* * *}$ & $0.116^{* * *}$ \\
\hline \multirow{2}{*}{\multicolumn{4}{|c|}{ Panel E: different samples }} \\
\hline & & & \\
\hline \multicolumn{4}{|c|}{ E1: Dropping observations with top $5 \%$ country pairs by migration flows } \\
\hline 0.020 & $0.047^{* * *}$ & $0.055^{* * *}$ & $0.118^{* *}$ \\
\hline$(0.015)$ & $(0.017)$ & $(0.019)$ & $(0.045)$ \\
\hline \multicolumn{4}{|c|}{ E2: Dropping observations with top $1 \%$ country pairs by migration flows } \\
\hline 0.020 & $0.047^{* * *}$ & $0.055^{* * *}$ & $0.121^{* * *}$ \\
\hline$(0.016)$ & $(0.018)$ & $(0.019)$ & $(0.046)$ \\
\hline E3: Dropping observations wit & ro migration $\mathrm{fl}$ & & \\
\hline 0.028 & $0.060^{* * *}$ & $0.066^{* * *}$ & $0.142^{* * *}$ \\
\hline$(0.017)$ & $(0.020)$ & $(0.021)$ & $(0.049)$ \\
\hline
\end{tabular}

Note: Columns (1)-(3) report the coefficient of the interaction term between temperature and agricultural dependence, based on specification similar to the one reported in column (3) in Table 2. Each column represents different definitions of agricultural countries, where the top $33 \%$, top $25 \%$, or top $20 \%$ agricultural countries are assigned with 1 , and the remaining countries are assigned with 0. Column (4) use a continuous measure of agricultural value added as \% of GDP instead of a agricultural dummy. Robust standard errors clustered by origin countries are reported in parentheses. $* * *, * *$, and $*$ denote significance at the $1 \%, 5 \%$, and $10 \%$ levels, respectively. 
Table 4: Temperature effects by popularity of migration routes between origins and destinations

\begin{tabular}{lllll}
\hline & $(1)$ & $(2)$ & $(3)$ & $(4)$ \\
\hline Temperature & 0.019 & 0.003 & -0.001 & 0.002 \\
& $(0.012)$ & $(0.011)$ & $(0.012)$ & $(0.010)$ \\
Temperature x Agriculture & 0.020 & -0.007 & 0.028 & $0.063^{* *}$ \\
& $(0.023)$ & $(0.019)$ & $(0.027)$ & $(0.025)$ \\
Precipitation & $-0.001^{* *}$ & -0.000 & $0.001^{*}$ & -0.000 \\
& $(0.000)$ & $(0.000)$ & $(0.000)$ & $(0.000)$ \\
Precipitation x Agriculture & 0.001 & 0.001 & $0.002^{*}$ & 0.001 \\
& $(0.001)$ & $(0.001)$ & $(0.001)$ & $(0.001)$ \\
& & & & \\
Origin and destination log of lagged GDP per capita & Yes & Yes & Yes & Yes \\
Country-pair fixed effects & Yes & Yes & Yes & Yes \\
Destination and origin country-specific linear time trend & Yes & Yes & Yes & Yes \\
& & & & \\
Number of observations & 17923 & 24898 & 29398 & 33807 \\
Number of country pairs & 1677 & 1844 & 1821 & 1882 \\
Adjusted $R^{2}$ & 0.9 & 0.8855 & 0.8887 & 0.9302 \\
\hline
\end{tabular}

Note: We split the dataset into four parts determined by the popularity of destination countries (based on migration stock) for each origin country, where column (1) only includes destination countries with small migration stock from each origin country, and column (4) only includes destination countries with large migration stock from each origin country. Robust standard errors clustered by origin countries are reported in parentheses.

$* * *, * *$, and $*$ denote significance at the $1 \%, 5 \%$, and $10 \%$ levels, respectively. 
Table 5: Nonlinear weather effects on migration

\begin{tabular}{llll}
\hline & $(1)$ & $(2)$ & $(3)$ \\
\hline Growing season exposure $10-30^{\circ} \mathrm{C}$ & $0.012^{* * *}$ & $0.013^{* * *}$ & $0.008^{* *}$ \\
Growing season exposure $10-30^{\circ} \mathrm{C}$ x Agriculture & $(0.004)$ & $(0.004)$ & $(0.004)$ \\
Growing season exposure $30^{\circ} \mathrm{C}+$ & & 0.015 & -0.002 \\
& & $(0.020)$ & $(0.021)$ \\
Growing season exposure $30^{\circ} \mathrm{C}+$ x Agriculture & $0.016^{* * *}$ & 0.005 & -0.001 \\
& $(0.005)$ & $(0.005)$ & $(0.005)$ \\
Precipitation & & $0.050^{* * *}$ & $0.035^{*}$ \\
& & $(0.018)$ & $(0.019)$ \\
Precipitation x Agriculture & 0.000 & -0.000 & -0.000 \\
& $(0.000)$ & $(0.000)$ & $(0.000)$ \\
Log of lagged origin GDP per capita & & $0.002^{*}$ & $0.002^{*}$ \\
& & $(0.001)$ & $(0.001)$ \\
Log of lagged destination GDP per capita & & & $-0.357^{* * *}$ \\
& & & $(0.045)$ \\
Country-pair fixed effects & & & $1.050^{* * *}$ \\
Origin and destination country-specific linear time trend & Yes & & $(0.088)$ \\
Number of Observations & 95,712 & 95,712 & 95,712 \\
Number of origin countries & 163 & 163 & 163 \\
Adjusted $R^{2}$ & 0.9369 & 0.9369 & 0.9374 \\
\hline
\end{tabular}

Note: Table reports regression results for the specification in equation (2). Robust standard errors clustered by origin country are reported in parentheses.

$* * *, * *$, and ${ }^{*}$ denote significance at the $1 \%, 5 \%$, and $10 \%$ levels, respectively. 
Table 6: Effects of weather on cereal yields

\begin{tabular}{|c|c|c|c|c|}
\hline & $(1)$ & $(2)$ & $(3)$ & $(4)$ \\
\hline Monthly mean temperature & $\begin{array}{l}-0.021^{* * *} \\
(0.006)\end{array}$ & $\begin{array}{l}-0.023^{* * *} \\
(0.006)\end{array}$ & & \\
\hline Growing season exposure $10-30^{\circ} \mathrm{C}$ & & & $\begin{array}{l}0.002 \\
(0.002)\end{array}$ & $\begin{array}{l}0.002 \\
(0.002)\end{array}$ \\
\hline Growing season exposure $30^{\circ} \mathrm{C}+$ & & & $\begin{array}{l}-0.024^{* * *} \\
(0.005)\end{array}$ & $\begin{array}{l}-0.023^{* * *} \\
(0.005)\end{array}$ \\
\hline Precipitation & $\begin{array}{l}0.000^{* *} \\
(0.000)\end{array}$ & $\begin{array}{l}0.000^{* *} \\
(0.000)\end{array}$ & $\begin{array}{l}-0.000 \\
(0.000)\end{array}$ & $\begin{array}{l}-0.000 \\
(0.000)\end{array}$ \\
\hline Log of lagged origin GDP per capita & & $\begin{array}{l}0.147^{* * *} \\
(0.052)\end{array}$ & & $\begin{array}{l}0.138^{* * *} \\
(0.051)\end{array}$ \\
\hline Observations & 4,517 & 4,517 & 4,517 & 4,517 \\
\hline Number of countries & 158 & 158 & 158 & 158 \\
\hline Adjusted R-squared & 0.9343 & 0.9349 & 0.9350 & 0.9355 \\
\hline
\end{tabular}

Note: All specifications include country fixed effects. Growing season exposure times are in 100 hours. Robust standard errors in parentheses.

$* * *, * *$, and $*$ denote significance at the $1 \%, 5 \%$, and $10 \%$ levels, respectively. 
Table 7: Adding latitude-temperature and GDP-temperature interactions

\begin{tabular}{|c|c|c|c|c|c|c|}
\hline & $(1)$ & $(2)$ & $(3)$ & $(4)$ & $(5)$ & $(6)$ \\
\hline Temperature & $\begin{array}{l}0.004 \\
(0.008)\end{array}$ & $\begin{array}{l}0.011 \\
(0.008)\end{array}$ & $\begin{array}{l}0.004 \\
(0.008)\end{array}$ & $\begin{array}{l}-0.130^{*} \\
(0.067)\end{array}$ & $\begin{array}{l}-0.228^{* * *} \\
(0.084)\end{array}$ & $\begin{array}{l}-0.369^{* *} \\
(0.182)\end{array}$ \\
\hline Precipitation & $\begin{array}{l}0.000 \\
(0.000)\end{array}$ & $\begin{array}{l}-0.000 \\
(0.000)\end{array}$ & $\begin{array}{l}-0.000 \\
(0.000)\end{array}$ & $\begin{array}{l}-0.002 \\
(0.003)\end{array}$ & $\begin{array}{l}-0.002 \\
(0.003)\end{array}$ & $\begin{array}{l}0.014 \\
(0.009)\end{array}$ \\
\hline Temperature x Agriculture & $\begin{array}{l}0.046^{* *} \\
(0.018)\end{array}$ & & $\begin{array}{l}0.051^{* *} \\
(0.021)\end{array}$ & & $\begin{array}{l}0.109^{* * *} \\
(0.028)\end{array}$ & $\begin{array}{l}0.121^{* * *} \\
(0.026)\end{array}$ \\
\hline Precipitation x Agriculture & $\begin{array}{l}0.001 \\
(0.001)\end{array}$ & & $\begin{array}{l}0.001 \\
(0.001)\end{array}$ & & $\begin{array}{l}0.002^{*} \\
(0.001)\end{array}$ & $\begin{array}{l}0.002 \\
(0.001)\end{array}$ \\
\hline Temperature $\mathrm{x}$ Latitude & & $\begin{array}{l}0.002 \\
(0.016)\end{array}$ & $\begin{array}{l}-0.020 \\
(0.018)\end{array}$ & & & \\
\hline Precipitation $\mathrm{x}$ Latitude & & $\begin{array}{l}0.001 * * \\
(0.001)\end{array}$ & $\begin{array}{l}0.001 \\
(0.001)\end{array}$ & & & \\
\hline Temperature x GDP & & & & $\begin{array}{l}0.017^{* *} \\
(0.007)\end{array}$ & $\begin{array}{l}0.026^{* * *} \\
(0.009)\end{array}$ & $\begin{array}{l}0.058 \\
(0.047)\end{array}$ \\
\hline Precipitation x GDP & & & & $\begin{array}{l}0.000 \\
(0.000)\end{array}$ & $\begin{array}{l}0.000 \\
(0.000)\end{array}$ & $\begin{array}{l}-0.004^{*} \\
(0.002)\end{array}$ \\
\hline Temperature x Squared GDP & & & & & & $\begin{array}{l}-0.002 \\
(0.003)\end{array}$ \\
\hline Precipitation x Squared GDP & & & & & & $\begin{array}{l}0.000^{*} \\
(0.000)\end{array}$ \\
\hline Squared Origin GDP per capita & & & & & & $\begin{array}{l}0.009 \\
(0.075)\end{array}$ \\
\hline Log of lagged destination GDP per capita & $\begin{array}{l}1.081^{* * *} \\
(0.097)\end{array}$ & $\begin{array}{l}1.072^{* * *} \\
(0.097)\end{array}$ & $\begin{array}{l}1.080 * * * \\
(0.097)\end{array}$ & $\begin{array}{l}1.060 * * * \\
(0.098)\end{array}$ & $\begin{array}{l}1.080^{* * *} \\
(0.098)\end{array}$ & $\begin{array}{l}1.079 * * * \\
(0.096)\end{array}$ \\
\hline Log of lagged origin GDP per capita & $\begin{array}{l}-0.360^{* * *} \\
(0.088)\end{array}$ & $\begin{array}{l}-0.365^{* * *} \\
(0.088)\end{array}$ & $\begin{array}{l}-0.360^{* * *} \\
(0.087)\end{array}$ & $\begin{array}{l}-0.755^{* * *} \\
(0.201)\end{array}$ & $\begin{array}{l}-0.934^{* * *} \\
(0.227)\end{array}$ & $\begin{array}{l}-1.093 \\
(1.120)\end{array}$ \\
\hline Number of observations & 95,712 & 95,712 & 95,712 & 95,712 & 95,712 & 95,712 \\
\hline Number of country pairs & 6156 & 6156 & 6156 & 6156 & 6156 & 6156 \\
\hline Adjusted $R^{2}$ & 0.9374 & 0.9374 & 0.9374 & 0.9374 & 0.9375 & 0.9375 \\
\hline
\end{tabular}

Note: "GDP" means GDP per capita in source countries. All columns also control for the log of lagged GDP per capita in origin and destination countries. Column (6) additionally controls for the squared term of GDP. Robust standard errors clustered at the origin country level are reported in parentheses.

$* * *, * *$, and $*$ denote significance at the $1 \%, 5 \%$, and $10 \%$ levels, respectively. 
Table 8: Effects of weather on GDP per capita

\begin{tabular}{|c|c|c|c|c|}
\hline & (1) & $(2)$ & $(3)$ & $(4)$ \\
\hline Temperature & $\begin{array}{l}0.032^{* * *} \\
(0.011)\end{array}$ & $\begin{array}{l}0.026^{* *} \\
(0.012)\end{array}$ & & \\
\hline Temperature x Agriculture & $\begin{array}{l}-0.102^{* *} \\
(0.044)\end{array}$ & $\begin{array}{c}-0.090^{*} \\
(0.046)\end{array}$ & & \\
\hline Precipitation & $\begin{array}{l}-0.000 \\
(0.000)\end{array}$ & $\begin{array}{l}-0.000 \\
(0.000)\end{array}$ & $\begin{array}{l}-0.000 \\
(0.000)\end{array}$ & $\begin{array}{l}-0.000 \\
(0.000)\end{array}$ \\
\hline Precipitation x Agriculture & $\begin{array}{c}-0.002^{*} \\
(0.001)\end{array}$ & $\begin{array}{c}-0.003^{*} \\
(0.001)\end{array}$ & $\begin{array}{l}-0.003^{* *} \\
(0.001)\end{array}$ & $\begin{array}{l}-0.003^{* *} \\
(0.001)\end{array}$ \\
\hline Growing season exposure $10-30^{\circ} \mathrm{C}$ & & & $\begin{array}{l}0.010^{*} \\
(0.006)\end{array}$ & $\begin{array}{l}0.008 \\
(0.007)\end{array}$ \\
\hline Growing season exposure $10-30^{\circ} \mathrm{C}$ x Agriculture & & & $\begin{array}{l}0.014 \\
(0.015)\end{array}$ & $\begin{array}{l}0.009 \\
(0.016)\end{array}$ \\
\hline Growing season exposure $30^{\circ} \mathrm{C}+$ & & & $\begin{array}{l}0.011 \\
(0.008)\end{array}$ & $\begin{array}{l}0.009 \\
(0.010)\end{array}$ \\
\hline Growing season exposure $30^{\circ} \mathrm{C}+\mathrm{x}$ Agriculture & & & $\begin{array}{l}-0.033^{* *} \\
(0.014)\end{array}$ & $\begin{array}{c}-0.032^{* *} \\
(0.014)\end{array}$ \\
\hline Country fixed effects & Yes & Yes & Yes & Yes \\
\hline Global time trend & Yes & No & Yes & No \\
\hline Time fixed effects & No & Yes & No & Yes \\
\hline Observations & 4,707 & 4,707 & 4,707 & 4,707 \\
\hline Number of country & 161 & 161 & 161 & 161 \\
\hline Adjusted $R^{2}$ & 0.9668 & 0.9685 & 0.9668 & 0.9684 \\
\hline
\end{tabular}

Note: The dependent variable is the natural logarithm of GDP per capita. Growing season exposure times are in 100 hours. Robust standard errors clustered at the country level are reported in parentheses.

$* * *, * *$, and $*$ denote significance at the $1 \%, 5 \%$, and $10 \%$ levels, respectively. 


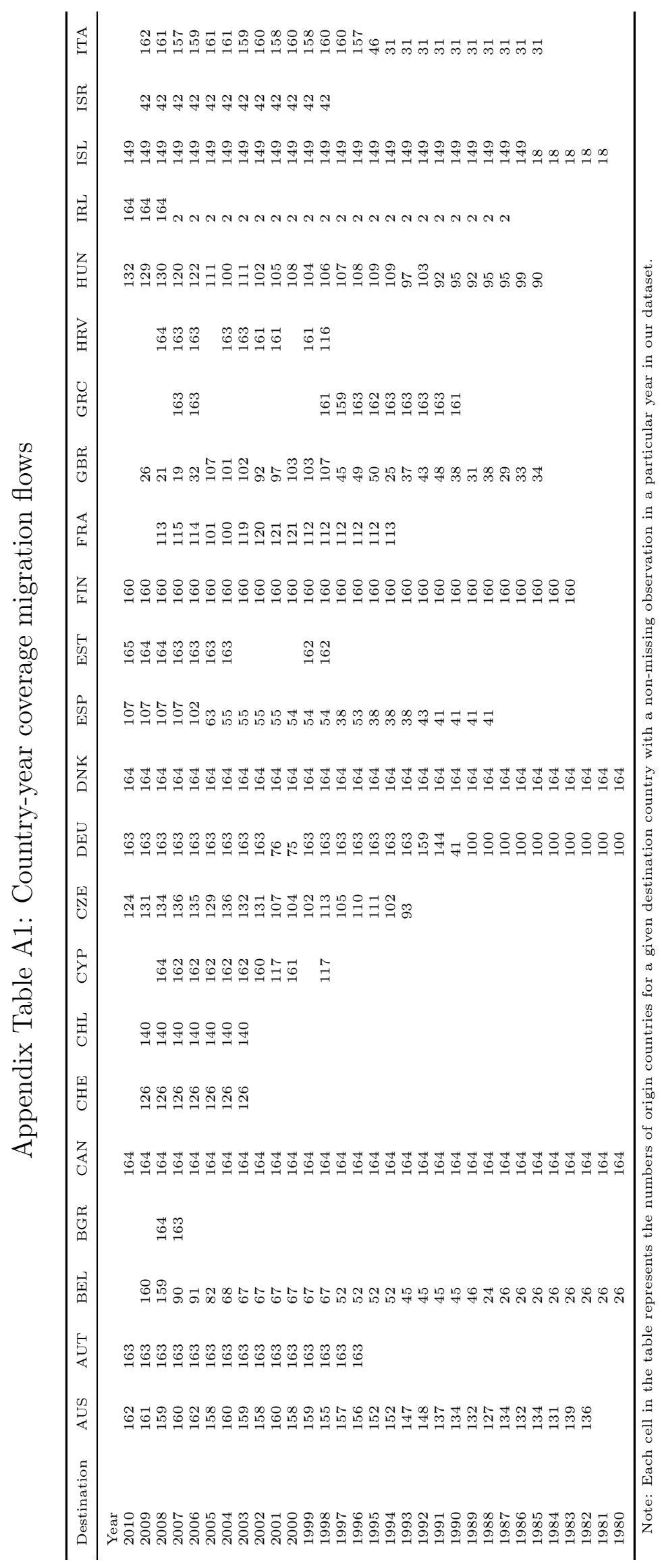




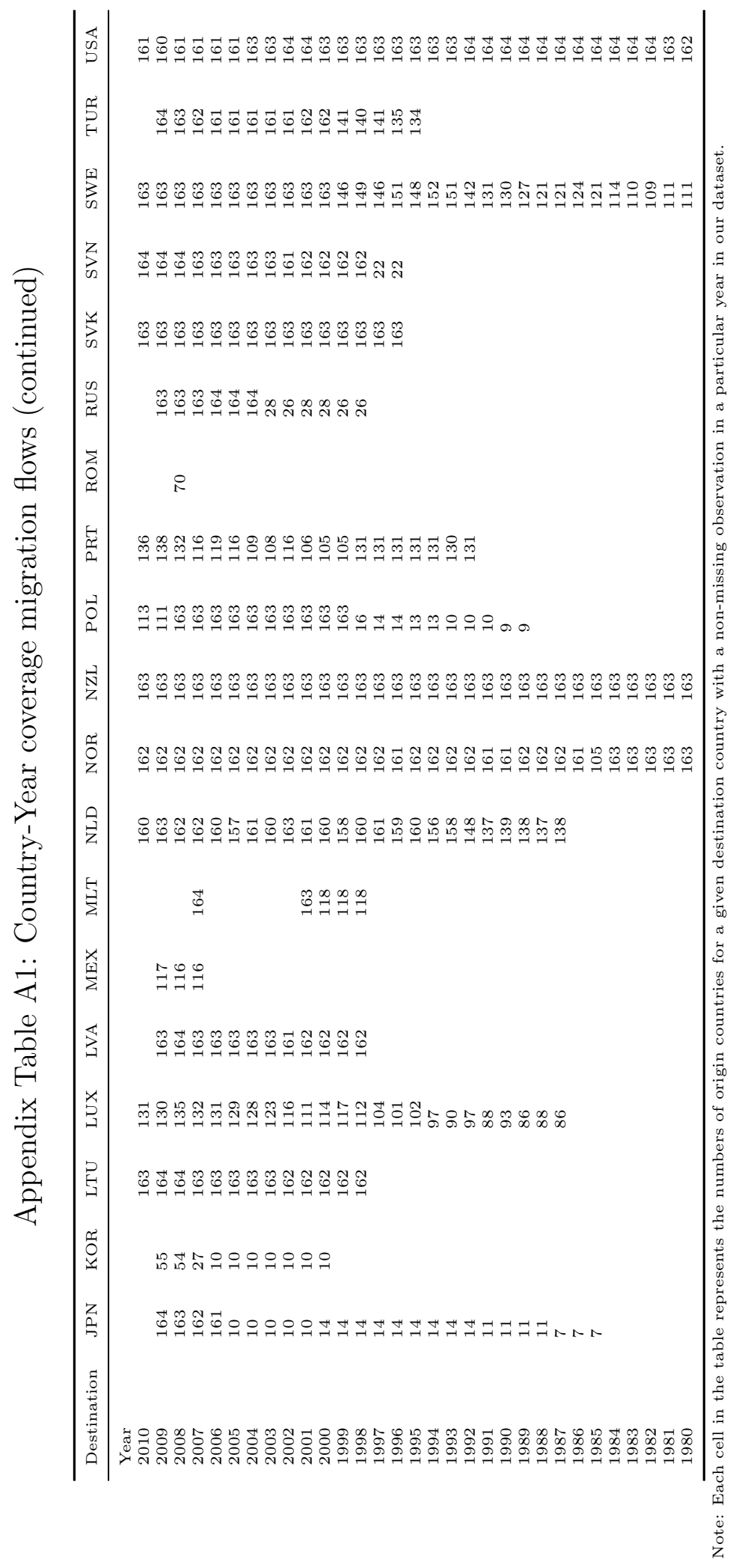


Appendix Table A2: Definitions of migration flows

\begin{tabular}{ll}
\hline Destinations & Definition of "immigrant" based on \\
\hline Australia & Country of Birth \\
Austria & Citizenship \\
Belgium & Citizenship \\
Bulgaria & Citizenship \\
Canada & Country of Birth \\
Chile & Citizenship \\
Cyprus & Citizenship \\
Czech Republic & Citizenship \\
Denmark & Citizenship \\
Estonia & Citizenship \\
Finland & Citizenship \\
France & Citizenship \\
Germany & Citizenship \\
Greece & Citizenship \\
Hungary & Citizenship \\
Iceland & Citizenship \\
Ireland & Country of Birth \\
Israel & Citizenship \\
Italy & Citizenship \\
Japan & Citizenship \\
Korea & Citizenship \\
Latvia & Citizenship \\
Lithuania & Citizenship \\
Luxembourg & Citizenship \\
Malta & Citizenship \\
Mexico & Citizenship \\
Netherlands & Country of Birth \\
New Zealand & Last Permanent Residence \\
Norway & 1979-1984 Country of Origin, 1985-2010 Citizenship \\
Poland & Country of Origin \\
Portugal & Citizenship \\
Romania & Citizenship \\
Russian Federation & Citizenship \\
Slovak Republic & Country of Origin \\
Slovenia & Citizenship \\
Spain & Country of Origin \\
Sweden & Citizenship \\
Switzerland & Citizenship \\
Turkey & Citizenship \\
United Kingdom & Citizenship \\
United States & Country of Birth \\
\hline
\end{tabular}




\section{Appendix Table A3: Effect of temperature on outmigration: subgroup regression results}

\begin{tabular}{|c|c|c|c|}
\hline $\begin{array}{l}\text { Groups of coun } \\
\text { (1) Below first } \\
\text { quartile (Q1) }\end{array}$ & $\begin{array}{l}\text { tries categorized } \\
\text { (2) between Q1 } \\
\text { and median }\end{array}$ & $\begin{array}{l}\text { agriculture dependence } \\
(3) \text { between } \\
\text { median and Q3 }\end{array}$ & (4) above Q3 \\
\hline \multicolumn{4}{|l|}{ Panel A: Baseline specification } \\
\hline 0.004 & 0.006 & 0.007 & $0.040^{* *}$ \\
\hline$(0.007)$ & $(0.016)$ & $(0.018)$ & $(0.017)$ \\
\hline \multicolumn{4}{|c|}{ Panel B: Different control variables } \\
\hline \multicolumn{4}{|c|}{ B1: Controlling for lagged one year temperature and precipitation } \\
\hline 0.008 & 0.009 & 0.004 & $0.028^{*}$ \\
\hline$(0.007)$ & $(0.016)$ & $(0.016)$ & $(0.016)$ \\
\hline \multicolumn{4}{|c|}{ B2: Controlling for lagged temperature and precipitation up to five years } \\
\hline 0.006 & 0.019 & 0.008 & $0.031^{*}$ \\
\hline$(0.008)$ & $(0.018)$ & $(0.017)$ & $(0.017)$ \\
\hline \multicolumn{4}{|c|}{ B3: Controlling for the log of lagged migration stock } \\
\hline 0.004 & 0.007 & 0.013 & $0.042^{* *}$ \\
\hline$(0.008)$ & $(0.016)$ & $(0.017)$ & $(0.017)$ \\
\hline \multicolumn{4}{|c|}{ B4: Controlling for the log of lagged one year migration rate } \\
\hline 0.004 & 0.010 & $0.015^{*}$ & $0.029^{* *}$ \\
\hline$(0.006)$ & $(0.014)$ & $(0.009)$ & $(0.012)$ \\
\hline \multicolumn{4}{|c|}{ B5: Controlling for origin country-specific quadratic time trend } \\
\hline $0.019^{* *}$ & 0.012 & 0.009 & $0.039^{* *}$ \\
\hline$(0.008)$ & $(0.016)$ & $(0.016)$ & $(0.016)$ \\
\hline \multicolumn{4}{|c|}{ B6: Controlling for both origin and destination country fixed effects } \\
\hline 0.004 & 0.006 & 0.007 & $0.040^{* *}$ \\
\hline$(0.007)$ & $(0.016)$ & $(0.018)$ & $(0.017)$ \\
\hline \multicolumn{4}{|c|}{ B7: Adding year fixed effects and its interaction with baseline characteristics } \\
\hline 0.002 & 0.007 & 0.014 & $0.040^{* *}$ \\
\hline$(0.010)$ & $(0.016)$ & $(0.015)$ & $(0.018)$ \\
\hline \multicolumn{4}{|c|}{ B8: Controlling for destination country weather } \\
\hline 0.007 & 0.008 & 0.009 & $0.041^{* *}$ \\
\hline$(0.008)$ & $(0.016)$ & $(0.018)$ & $(0.017)$ \\
\hline \multicolumn{4}{|c|}{ Panel C: different dependent/independent variables } \\
\hline \multicolumn{4}{|c|}{ C1: Using the natural logarithm of migration flows as dependent variable } \\
\hline 0.004 & 0.006 & 0.007 & $0.040^{* *}$ \\
\hline$(0.008)$ & $(0.016)$ & $(0.018)$ & $(0.017)$ \\
\hline \multicolumn{4}{|c|}{$\mathrm{C} 2$ : Using lagged temperature and precipitation as independent variable } \\
\hline-0.002 & -0.007 & 0.026 & $0.036^{* *}$ \\
\hline$(0.007)$ & $(0.017)$ & $(0.015)$ & $(0.018)$ \\
\hline \multicolumn{4}{|c|}{ Panel D: different regression techniques } \\
\hline \multicolumn{4}{|c|}{ D1: Regressions weighted by the natural logarithm of origin country population } \\
\hline 0.005 & 0.004 & 0.009 & $0.043^{* *}$ \\
\hline$(0.007)$ & $(0.017)$ & $(0.018)$ & $(0.018)$ \\
\hline \multicolumn{4}{|c|}{ D2: Clustering at the country-pair level } \\
\hline 0.004 & 0.006 & 0.007 & $0.040^{* * *}$ \\
\hline & $(0.010)$ & $(0.010)$ & $(0.012)$ \\
\hline \multicolumn{4}{|l|}{ Panel E: different samples } \\
\hline \multicolumn{4}{|c|}{ E1: Dropping observations with top $5 \%$ country pairs by migration flows } \\
\hline 0.000 & 0.004 & 0.002 & $0.036^{* *}$ \\
\hline$(0.008)$ & $(0.015)$ & $(0.014)$ & $(0.016)$ \\
\hline \multicolumn{4}{|c|}{ E2: Dropping observations with top $1 \%$ country pairs by migration flows } \\
\hline 0.003 & 0.006 & 0.006 & $0.039 * *$ \\
\hline$(0.007)$ & $(0.016)$ & $(0.016)$ & $(0.017)$ \\
\hline \multicolumn{4}{|c|}{ E3: Dropping observations with zero migration flows } \\
\hline 0.003 & 0.007 & 0.008 & $0.064^{* * *}$ \\
\hline$(0.007)$ & $(0.015)$ & $(0.019)$ & $(0.019)$ \\
\hline
\end{tabular}

Note: The regression specification is similar to Equation (1) except that the interaction terms of temperature/precipicipation and agriculture are not included. The coefficients of temperature are reported here. Each column represents different country groups ranked by agricultural dependence. Robust standard errors clustered by origin country are reported in parentheses unless otherwise noted.

$* * *, * *$, and ${ }^{*}$ denote significance at the $1 \%, 5 \%$, and $10 \%$ levels, respectively. 